\title{
Toxicity Assessment of Fe-Mn-Al Ternary Alloys Using a Probit Dose-Response Model and an Augmented Simplex Design
}

\author{
Shih-Hang Chang*1, Bor-Yann Chen and Chin-He Chiang*2 \\ Department of Chemical and Materials Engineering, National I-Lan University, I-Lan 260, Taiwan
}

\begin{abstract}
This study establishes a toxicity assessment of the mixture of $\mathrm{Fe}^{3+}, \mathrm{Mn}^{2+}$, and $\mathrm{Al}^{3+}$ ions by employing a Probit dose-response model and an augmented simplex design. The toxicity of individual $\mathrm{Fe}^{3+}, \mathrm{Mn}^{2+}$, and $\mathrm{Al}^{3+}$ metal ions with respect to Escherichia coli $\mathrm{DH} 5 \alpha$ is in the order of $\mathrm{Mn}^{2+}>\mathrm{Fe}^{3+}>\mathrm{Al}^{3+}$. The mixture of $\mathrm{Fe}^{3+}, \mathrm{Mn}^{2+}$, and $\mathrm{Al}^{3+}$ ions shows a hump region and a saddle region in the $I C_{50}$ values contour plot. Fe-Mn-Al ternary alloys may possess a lower toxic risk when the ratio of released metal ions approaches the hump region of the contour plot. Fe$\mathrm{Mn}-\mathrm{Al}$ ternary alloys may present an increased toxic risk when the ratio of released metal ions gets close to the saddle regions of the contour plot. [doi:10.2320/matertrans.M2014108]
\end{abstract}

(Received March 25, 2014; Accepted October 30, 2014; Published December 25, 2014)

Keywords: iron-manganese-aluminum alloys, toxicity assessment, augmented simplex design, probit dose-response

\section{Introduction}

Fe-Cr-Ni stainless steels, Co-Cr based alloys, pure $\mathrm{Ti}$ metal, and Ti-6Al-4V alloys are traditionally used as biocompatible metallic materials in biomedical applications such as replacing hard tissue. ${ }^{1)}$ Among them, stainless steels are typically used as implant materials for normal medical and dental applications, joint replacement, fixation of bone fractures, and for orthopedic purposes because of their low cost, good mechanical properties and excellent corrosion resistance. ${ }^{2-4)}$ However, interactions between stainless steel and living tissues usually lead to corrosion of the chromium oxide layer and release nickel ions, which may disturb the proliferation and differentiation relationship in osteoblastic human alveolar bone cell cultures and induce undesirable allergies or cancer. $^{5-7)}$ Recently, shape memory alloys (SMAs) have been extensively developed in advanced medical applications because of their unique shape memory effect and superelasticity. ${ }^{8)}$ Compared to other SMAs, nickeltitanium (TiNi) SMAs are the most widely investigated because they could offer good biofunctionality for particular biomedical applications, such as in laparoscopic surgery, intracoronary stents, ligament replacement, shape memory microvalves for the control of drug delivery, and for bone stamp and osteosynthesis devices. ${ }^{9-11)}$ Unfortunately, the degradation of TiNi SMAs implants also involves the release of nickel ions, severely restricting their practical biomedical applications. $^{12)}$

The biocompatibility characteristics of biomaterials should be carefully considered when they are used for implant materials. Shettlmore and Bundy ${ }^{13)}$ reported that the toxicity of aqueous metal solutions is representative of the ionic degradation products of orthopedically implanted $316 \mathrm{~L}$ stainless steel by a Microtox ${ }^{\circledR}$ bacterial bioluminescence assay. Their study developed a mathematical model to predict the toxicity of mixtures of $\mathrm{Ni}^{2+}, \mathrm{Cr}^{3+}$, and $\mathrm{Fe}^{3+}$ ions based on the proportions of the metal ions determined through selective leaching of $316 \mathrm{~L}$ stainless steel. They then proposed

${ }^{* 1}$ Corresponding author, E-mail: shchang@niu.edu.tw

${ }^{* 2}$ Graduate Student, National I-Lan University that the ions present in this ratio exhibit antagonistic interactions, resulting in a decrease in the toxicity of degradation products from $316 \mathrm{~L}$ stainless steel. The advantage of this method is that the toxicity of the implant materials can be rapidly and economically predicted and analyzed using bacteria prior to toxicology studies under in vivo conditions using animals. However, this method can only determine the toxicity of three-component $\mathrm{Fe}-\mathrm{Ni}-\mathrm{Cr}$ ionic systems at a specific concentration ratio. Consequently, it is extremely costly and time-consuming to determine the toxicities of other biomedical materials also composed of $\mathrm{Fe}, \mathrm{Cr}$, and $\mathrm{Ni}$ ions but at different proportions. In order to overcome this shortcoming, Chang et al. ${ }^{14)}$ established a toxicity assessment of the mixture of $\mathrm{Fe}^{3+}, \mathrm{Cr}^{3+}$, and $\mathrm{Ni}^{2+}$ ions using an augmented simplex design to verify the toxicity of releasing $\mathrm{Fe}^{3+}, \mathrm{Cr}^{3+}$, and $\mathrm{Ni}^{2+}$ at a various combination of concentrations.

Fe-Mn-Al alloys have attracted research attention for many years because of their specific properties, such as high strength, high ductility and good corrosion resistance; these alloys are economical and can be used to replace conventional Fe-Cr-Ni stainless steels. ${ }^{15-18)}$ Recently, Omori et al. reported that $\mathrm{Fe}-\mathrm{Mn}-\mathrm{Al}$ alloys with specific chemical compositions or with the addition of a small amount of $\mathrm{Ni}$ into polycrystalline $\mathrm{Fe}-\mathrm{Mn}-\mathrm{Al}$, can exhibit shape memory effect and superelasticity. ${ }^{19,20)}$ Consequently, Fe-Mn-Al alloys are promising candidates to serve biomaterials because they possess the advantages of both $\mathrm{Fe}-\mathrm{Cr}-\mathrm{Ni}$ stainless steels and TiNi SMAs, but contain a much lower nickel concentration. The main purpose of this study is therefore to investigate the toxicity effects of $\mathrm{Fe}^{3+}, \mathrm{Mn}^{2+}$ and $\mathrm{Al}^{3+}$ metal ions on bacteria (Escherichia coli $\mathrm{DH} 5 \alpha$ ) by Probit doseresponse analysis and augmented simplex design to simulate with an assess the toxicity of the mixture of $\mathrm{Fe}^{3+}, \mathrm{Mn}^{2+}$, and $\mathrm{Al}^{3+}$ ions at different concentration ratios.

\section{Experimental Procedures}

\subsection{Materials and methods}

The Fe, Mn, and Al metal ions used in this study were high-purity atomic absorption spectroscopy (AAS) standard 
solution $(1,000 \mathrm{mg} / \mathrm{L})$ purchased from Merck. Each AAS solution was diluted to various concentrations, and mixed with sodium citrate buffer solution, $0.5 \times \mathrm{LB}$, and deionized water to formulate metal ion solutions ranging between 0 and $1,000 \mathrm{mg} / \mathrm{L}$. The toxic levels of the selected ion concentrations for the Escherichia coli DH5 $\alpha$ were appropriate in the context of typical mammalian cells research reported before, in which the metallic ion concentrations were approximately $100 \mathrm{ppm} .{ }^{21-23)}$ The Escherichia coli DH5 $\alpha$ used in this study was provided by Professor Bor-Yann Chen, NIU, Taiwan. Escherichia coli DH5 $\alpha$ was pre-cultured in Luria-Bertani (LB) broth $(10 \mathrm{~g} / \mathrm{L}$ tryptone, $5 \mathrm{~g} / \mathrm{L}$ yeast extract, $10 \mathrm{~g} / \mathrm{L} \mathrm{NaCl}$ ) at $37^{\circ} \mathrm{C}, 125 \mathrm{rpm}$ for $12 \mathrm{~h}$. Cultured Escherichia coli $\mathrm{DH} 5 \alpha$ solutions were then added to each metal ion solution at a volume ratio of $1: 100$. The concentration of Escherichia coli DH5 $\alpha$ was determined by measuring the cell solution optical density $(O D)$ value every $30 \mathrm{~min}$ for the initial $5 \mathrm{~h}$, and then every $1 \mathrm{~h}$ up until $24 \mathrm{~h}$. The cell solution $O D$ value was measured at $600 \mathrm{~nm}\left(O D_{600}\right)$ in a spectrophotometer (GENESYS 20, Thermo Scientific) using cultured broth as the blank cuvette.

\subsection{Dose-response analysis}

The dose-response curves of $\mathrm{Fe}, \mathrm{Mn}$, and $\mathrm{Al}$ metal ions were analyzed using a Probit dose-response model. ${ }^{24)}$ The Probit dose-response model suggests that the tolerance capacity of bacteria in response to toxic material in a given population exhibits a log-normal distribution. The mid-point inhibitive concentration $\left(I C_{50}\right)$ on the dose-response curve is typically selected for metal ion toxicity comparisons because it is simpler to interpolate the mid-point $I C_{50}$ accurately than it is to make extrapolated estimates of $I C_{0}$ and $I C_{100}$. The semi-logarithmic plot of metal ion concentration as a function of the obtained response is assumed to behave as a linear relationship. Thus, the Probit dose-response model converts a sigmoidal-shaped dose-response curve into a linear normal equivalent deviation (NED) scale. For example, 50\% and $84.1 \%$ responses correspond to NED scale values of 0 and 1 , respectively. Additionally, a Probit unit $(P)$ in the model equals a NED scale value plus 5 . The concentration formulae are shown as follows: ${ }^{24-27)}$

$$
\begin{aligned}
Y & =A+B \log Z \\
P & =\frac{1}{2}\left[1+\operatorname{erf}\left(\frac{Y-5}{\sqrt{2}}\right)\right] \\
\operatorname{erf}(x) & \equiv \frac{2}{\sqrt{\pi}} \int_{0}^{x} e^{-\xi^{2}} d \xi
\end{aligned}
$$

where $A$ and $B$ are the intercept and Hill slope of the doseresponse relationship; $Z$ and $Y$ are the metal concentration $(\mathrm{mol} / \mathrm{L})$ and Probit unit, respectively; $P$ is the response $(\%)$ corresponding to the administered metal; $\operatorname{erf}(x)$ is an error function. Note that the response variable is normalized so as to be located between 0 and 1 . The conversion relationship for provoked response is given by Chen et al. ${ }^{25,26)}$ For example, $55 \%$ and $85 \%$ responses correspond to 5.13 and 6.04 Probit units, respectively. The relative growth rate can be determined from $\mu / \mu_{0}$, where $\mu$ denotes the maximum specific growth rate and the reference parameters $\mu_{0}$ are determined from growth curves of zero concentration of a metal-free culture. ${ }^{27)}$ The kinetic parameter $\mu$ is specifically

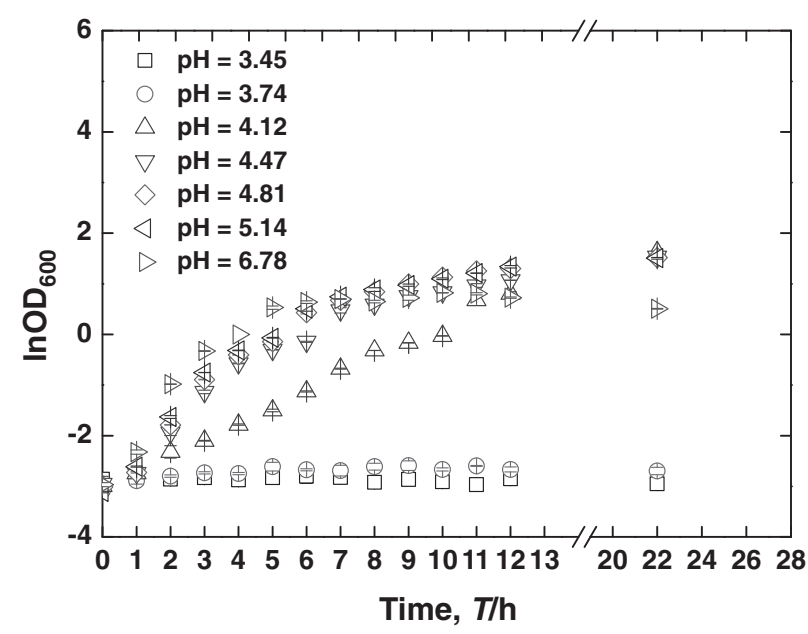

Fig. 1 The $\ln O D_{600}$ values of the Escherichia coli DH5 $\alpha$ solutions cultured in medium with various $\mathrm{pH}$ values as a function of time.

determined from the growth curves of the designed experimental cultures. Microbes in a metal-laden environment may exhibit a significant decrease in the growth rate of bacterial cultures. All inocula used in this study were selected from pre-cultures in metal-free media.

\section{Results and Discussion}

\subsection{Effect of pH values on the growth of Escherichia coli DH5 $\alpha$}

Figure 1 presents the $\ln O D_{600}$ values of Escherichia coli $\mathrm{DH} 5 \alpha$ solutions cultured in medium with various $\mathrm{pH}$ values from 3.45 to 6.78 as a function of time. Figure 1 shows that the $\ln O D_{600}$ values for the curves of $\mathrm{pH}=4.47,4.81,5.14$, and 6.78 all generally increase with culture time, indicating that Escherichia coli DH5 $\alpha$ grow prosperously when the $\mathrm{pH}$ values of the culture media are between 4.47 and 6.78 . Figure 1 also shows that the $\ln O D_{600}$ values for the curve of $\mathrm{pH}=4.12$ only slightly increase with the increase of culture time, suggesting that the growth of Escherichia coli DH5 $\alpha$ is retarded. Figure 1 also shows that the $\ln O D_{600}$ values for the curves of $\mathrm{pH}=3.54$ and 3.74 do not show appreciable difference throughout the culture time. This indicates that the growth of Escherichia coli DH5 $\alpha$ is totally inhibited when the $\mathrm{pH}$ values of the culture media are 3.54 and 3.74. Accordingly, in this study, we controlled the $\mathrm{pH}$ value of the culture medium at $\mathrm{pH}=4.8$ after mixing the metal ions solutions by adding appropriate volume of sodium citrate buffer solution to ensure the growth of Escherichia coli $\mathrm{DH} 5 \alpha$ will not be affected by the $\mathrm{pH}$ value of the culture medium.

\subsection{Tolerance capacity of bacteria in response to single metal ion}

Figure 2(a) plots the $\ln O D_{600}$ values of Escherichia coli $\mathrm{DH} 5 \alpha$ solutions added with $\mathrm{Al}^{3+}$ ion solutions of different concentrations as a function of time. The $\ln O D_{600}$ value of Escherichia coli $\mathrm{DH} 5 \alpha$ without adding any $\mathrm{Al}^{3+}$ ion (control group) is also plotted in Fig. 2(a) for comparison. As shown in Fig. 2(a), the $\ln O D_{600}$ values for each curve are extremely small in the first hour. The deferment of the Escherichia coli 

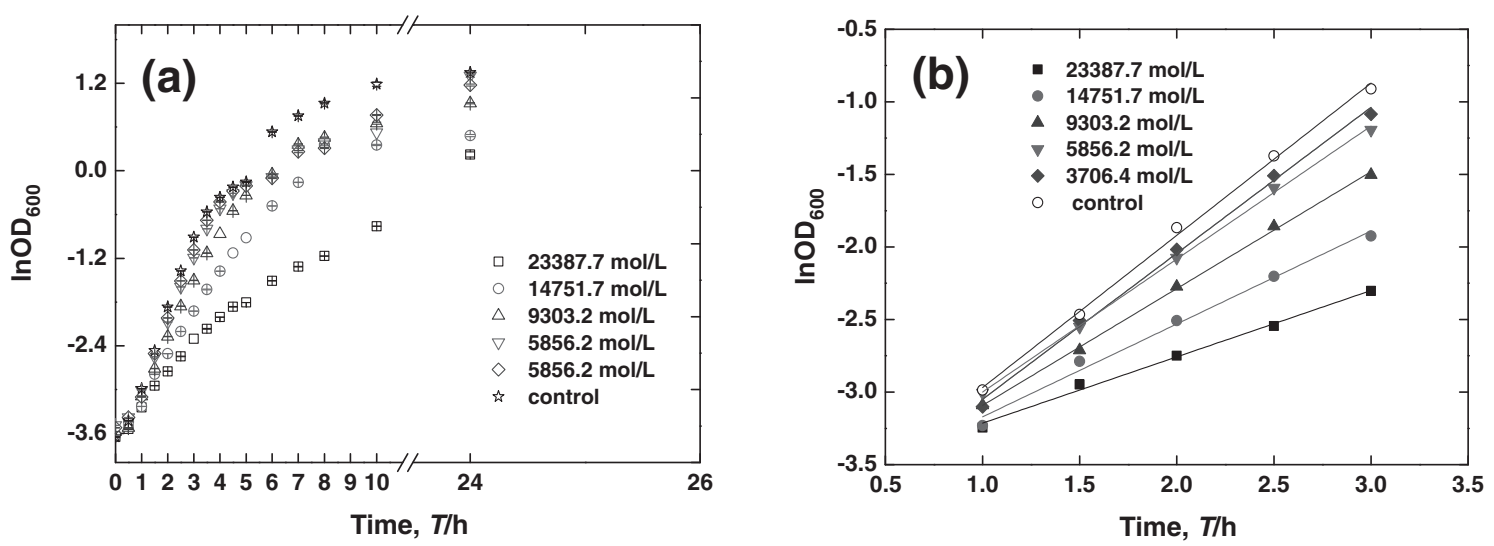

Fig. 2 (a) The $\ln O D_{600}$ values of the Escherichia coli DH5 $\alpha$ solutions added with $\mathrm{Al}^{3+}$ metal ion with different concentrations as a function of time. (b) The $\ln O D_{600}$ value as a function of time measured in the exponential growth stage for each curve in (a).
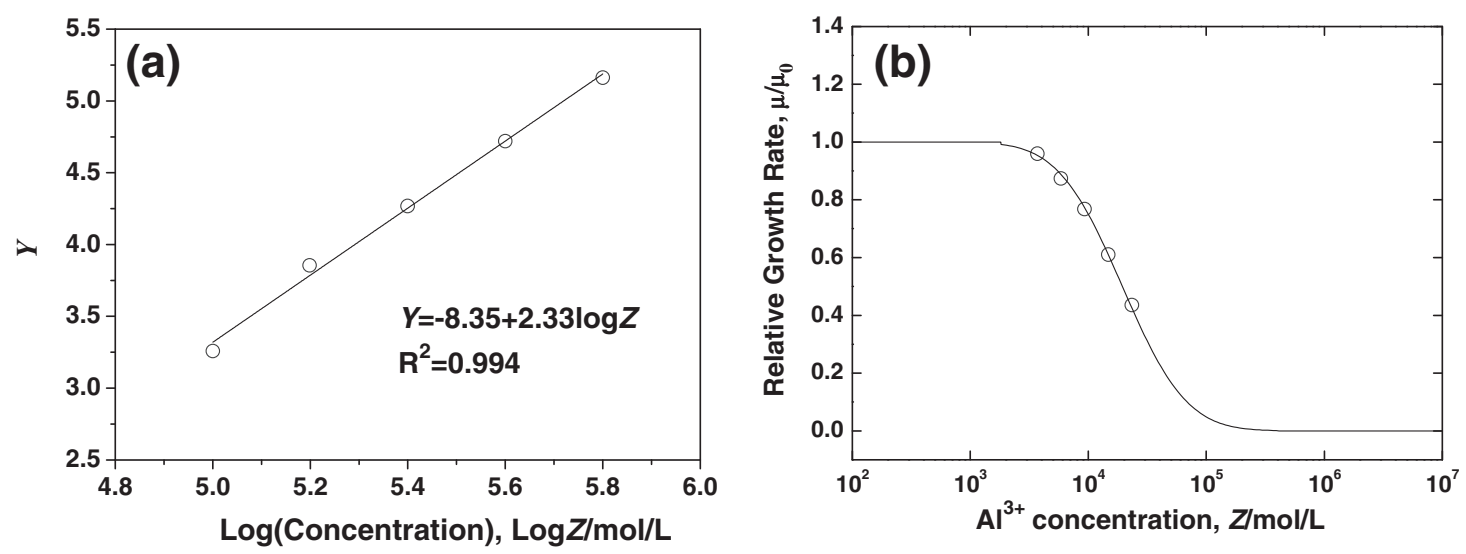

Fig. 3 (a) The relation between $Y$ value and concentration $Z$ and (b) relative growth rate curves of $\mathrm{Al}^{3+}$ metal ion predicted by the Probit model.

DH5 $\alpha$ growth at this stage is termed as the lag time. Thereafter, the $\ln O D_{600}$ values for each curve increase significantly until $5 \mathrm{~h}$, which indicates that Escherichia coli DH5 $\alpha$ exhibit an exponential growth at this stage. After $5 \mathrm{~h}$, on the other hand, the $\ln O D_{600}$ values for each curve gradually approach a static state until $24 \mathrm{~h}$. Figure 2(a) also shows that the $\ln O D_{600}$ values decrease with increasing $\mathrm{Al}^{3+}$ ion concentration when determined at the same time. This feature reveals that the addition of $\mathrm{Al}^{3+}$ ion into solutions significantly inhibits the growth of Escherichia coli DH5 $\alpha$. Figure 2(b) plots the $\ln O D_{600}$ values as a function of time for the exponential growth stage of each curve shown in Fig. 2(a). Figure 2(b) shows that each curve exhibits a linear relationship during exponential growth. Therefore, the specific growth rate, $\mu$, for Escherichia coli DH5 $\alpha$ with various concentrations of $\mathrm{Al}^{3+}$ ion can be determined from the slope of each fitting line. Meanwhile, the maximum specific growth rate $\mu_{0}$ can be determined from the slope of the fitting line of the control group. Accordingly, the response value can be calculated from the equation $\left(\mu_{0}-\mu\right) / \mu_{0}$ from Fig. 2(b), and then changed into Probit value $Y$ and plotted in Fig. 3(a). Consequently, as shown in Fig. 3(a), the relation between the value of $Y$ and concentration $Z$ can be calculated and plotted by means of the Probit model. From Fig. 3(a), the concentration formula for the $\mathrm{Al}^{3+}$ ion can be obtained from the fitting line as $Y=-8.35+2.33 \log Z\left(R^{2}=0.994\right)$. From this equation, the dose-response curve can be plotted from the relation between relative growth rate $\left(\mu / \mu_{0}\right)$, and concentration $Z$, as illustrated in Fig. 3(b). From Fig. 3(b), the $I C_{50}$ value for the $\mathrm{Al}^{3+}$ ion can be determined to be 19232.8 $\mathrm{mol} / \mathrm{L}$. In the same manner, the concentration formulae for $\mathrm{Fe}^{3+}$ and $\mathrm{Mn}^{2+}$ ions are determined to be $Y=-9.97+$ $2.60 \log Z\left(R^{2}=0.996\right)$ and $Y=-8.30+2.38 \log Z\left(R^{2}=\right.$ $0.993)$, respectively. Figure 4 plots all the dose-response curves for single $\mathrm{Fe}^{3+}, \mathrm{Mn}^{2+}$, and $\mathrm{Al}^{3+}$ ions. From Fig. 4, the $I C_{50}$ values for $\mathrm{Fe}^{3+}, \mathrm{Mn}^{2+}$, and $\mathrm{Al}^{3+}$ ions are 15692.9, 6891.4, and $19232.8 \mathrm{~mol} / \mathrm{L}$, respectively. This indicates that the toxicity of these metal ions with respect to Escherichia coli $\mathrm{DH} 5 \alpha$ is in an order of $\mathrm{Mn}^{2+}>\mathrm{Fe}^{3+}>\mathrm{Al}^{3+}$.

\subsection{Tolerance capacity of bacteria in response to solu- tions containing two or three kinds of metal ions}

Figures 5(a) and 5(b) plot the dose-response curves for solutions containing two or three kinds of metal ions, respectively, with different specific concentration ratios. From Fig. 5(a), the $I C_{50}$ value for $\mathrm{Fe}^{3+}: \mathrm{Mn}^{2+}=1: 1$, $\mathrm{Fe}^{3+}: \mathrm{Al}^{3+}=1: 1$, and $\mathrm{Mn}^{2+}: \mathrm{Al}^{3+}=1: 1$ can be determined to be $14590.4,20379.8$, and $32886.5 \mathrm{~mol} / \mathrm{L}$, respectively. This indicates that the toxicities of the solutions containing two kinds of metal ions in the ratios of $\mathrm{Fe}^{3+}: \mathrm{Al}^{3+}=1: 1$ and $\mathrm{Fe}^{3+}: \mathrm{Mn}^{2+}=1: 1$ are comparable and are slightly higher than that in the ratio of $\mathrm{Mn}^{2+}$ : 


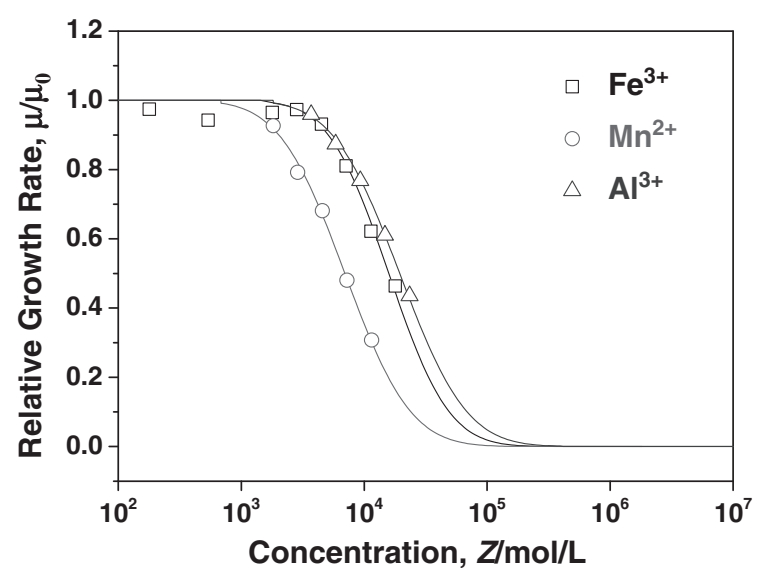

Fig. 4 Relative growth rate curves of $\mathrm{Fe}^{3+}, \mathrm{Mn}^{2+}$ and $\mathrm{Al}^{3+}$ metal ions predicted by the Probit model.

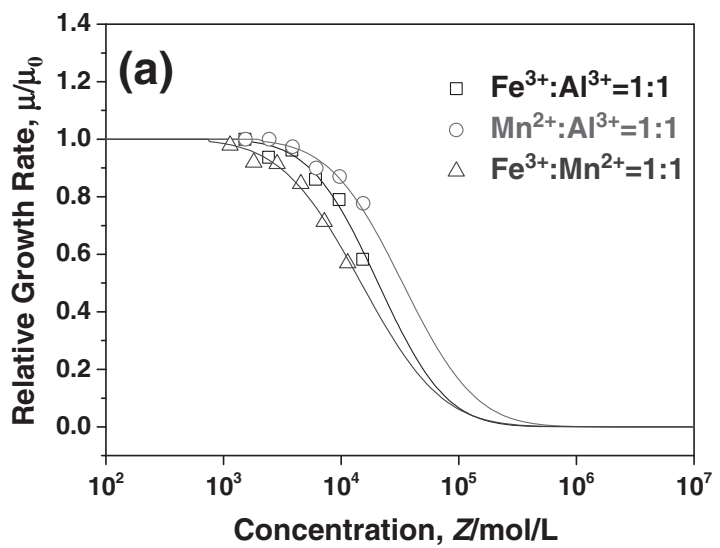

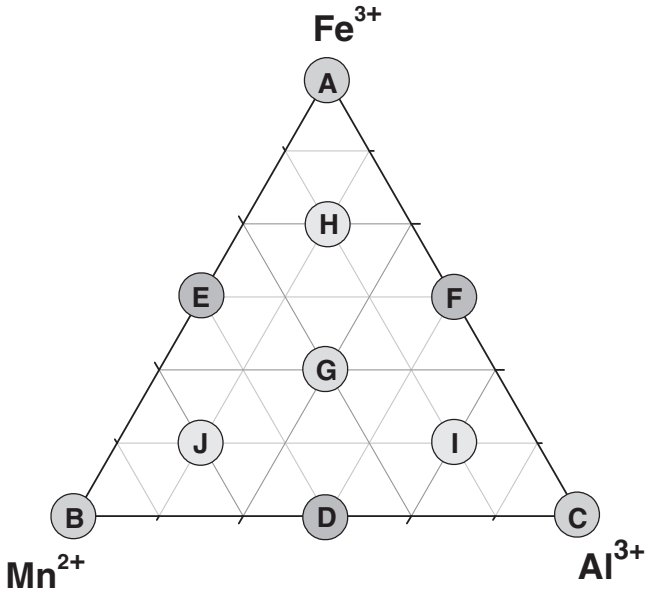

Fig. 6 A schematic diagram of triangle ternary graph for the augmented mixture design of $\mathrm{Fe}^{3+}, \mathrm{Mn}^{2+}$ and $\mathrm{Al}^{3+}$ ions.

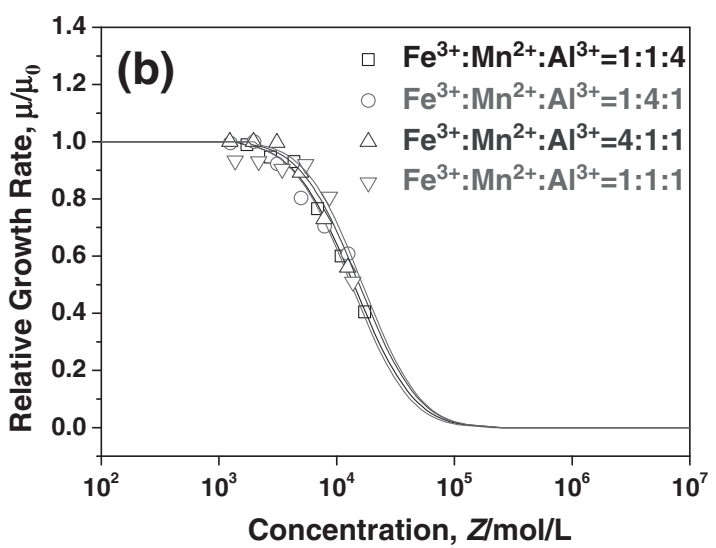

Fig. 5 Relative growth rate curves of Fe-Mn-Al solutions containing (a) two and (b) three of $\mathrm{Fe}^{3+}, \mathrm{Mn}^{2+}$ and $\mathrm{Al}^{3+}$ ions predicted by the Probit model.

$\mathrm{Al}^{3+}=1: 1$. Since $\mathrm{Mn}^{2+}$ ion possesses the highest toxicity compared to $\mathrm{Al}^{3+}$ and $\mathrm{Fe}^{3+}$ ions, this unexpected result corresponds to the fact that the interactions between these metal ions may cause synergism, antagonism, or additivity effects in the solutions containing two kinds of metal ions. From Fig. 5(b), the $I C_{50}$ values for $\mathrm{Fe}^{3+}: \mathrm{Mn}^{2+}: \mathrm{Al}^{3+}=$ $1: 1: 1, \quad \mathrm{Fe}^{3+}: \mathrm{Mn}^{2+}: \mathrm{Al}^{3+}=1: 1: 4, \quad \mathrm{Fe}^{3+}: \mathrm{Mn}^{2+}:$ $\mathrm{Al}^{3+}=1: 4: 1$, and $\mathrm{Fe}^{3+}: \mathrm{Mn}^{2+}: \mathrm{Al}^{3+}=4: 1: 1$ can be determined to be $20693.9,21958.3,14332.8$, and 17168.3 $\mathrm{mol} / \mathrm{L}$, respectively. The fact that the toxicity of $\mathrm{Fe}^{3+}$ : $\mathrm{Mn}^{2+}: \mathrm{Al}^{3+}=1: 4: 1$ is slightly higher than other concentration ratios can be assigned to the higher toxicity of the $\mathrm{Mn}^{2+}$ ion. However, this effect is not significant because the complex toxicity interactions between these three metal ions are difficult to determine.

\subsection{Toxicity assessment of a mixture of $\mathrm{Fe}^{3+}, \mathrm{Mn}^{2+}$, and $\mathrm{Al}^{3+}$ ions}

The toxicity of the mixture of $\mathrm{Fe}^{3+}, \mathrm{Mn}^{2+}$, and $\mathrm{Al}^{3+}$ ions on Escherichia coli DH5 $\alpha$ can be further assessed by an augmented simplex design, which is the most common type of design for experiments involving mixtures. As shown in Fig. 6, the factorial space constituted by all possible concentration ratios of $\mathrm{Fe}^{3+}, \mathrm{Mn}^{2+}$, and $\mathrm{Al}^{3+}$ ions is a triangle, of which the vertices correspond to $\mathrm{Fe}^{3+}$ (point $\mathrm{A}$ ), $\mathrm{Mn}^{2+}$ (point $\mathrm{B}$ ), and $\mathrm{Al}^{3+}$ (point $\mathrm{C}$ ) ions. In addition to the vertices, the triangle's central point (point $G$ ), the medium points along the lines connecting the vertices (points D-F), and the medium points between the central point and the vertices (points $\mathrm{H}-\mathrm{J}$ ) are also considered in the augmented simplex design. ${ }^{28)}$ All the responses of points $\mathrm{A}$ to $\mathrm{J}$ are also determined as the $I C_{50}$ values described in Sections 3.2 and 3.3. These response values can be formulated by a typical quadratic model as

$$
\begin{aligned}
I C_{50}= & 17094.97 x+7340.87 y+18218.45 z \\
& -4222.14 x y-8674.81 x z+57049.74 y z
\end{aligned}
$$

where $x, y$ and $z$ represent the concentration ratios of $\mathrm{Fe}^{3+}$, $\mathrm{Mn}^{2+}$, and $\mathrm{Al}^{3+}$, respectively. Figures 7(a) and 7(b) show the three-dimensional plot and the two-dimensional contour plot, respectively, of the formulated quadratic model. As shown in Fig. 7 , the $I C_{50}$ values show a saddle region close to pure $\mathrm{Mn}$ (denoted as region $\mathrm{I}$ ) and a hump region around $\mathrm{Mn}^{2+}: \mathrm{Al}^{3+}=1: 1$ (denoted as region II). Accordingly, we can predict that the implant material may increase the toxicity risk when the ratio of metal ions released from it in human tissue is close to region I. On the other hand, implant material may possess a lower toxic risk for prostheses applications 
(a)

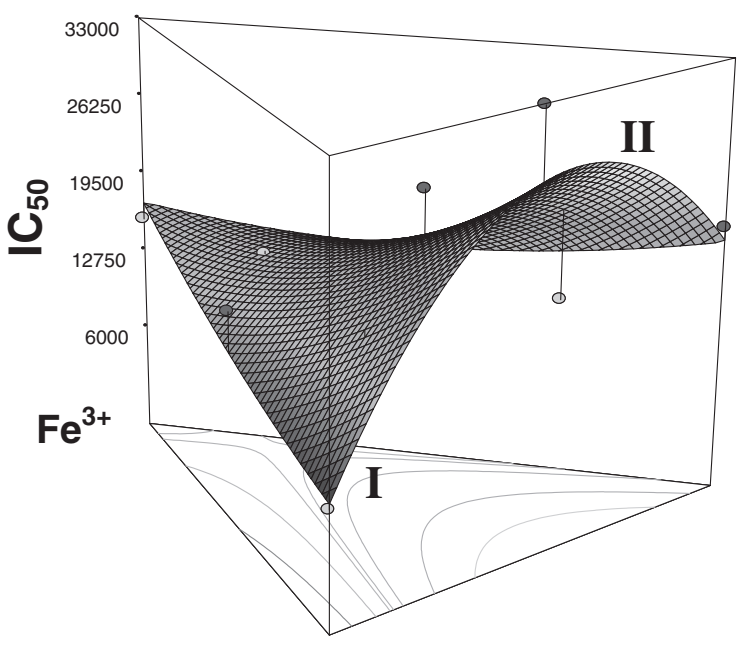

(b) $\mathbf{A l}^{3+}$

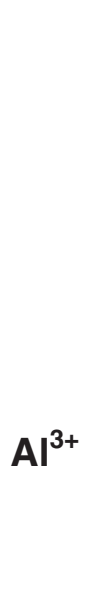

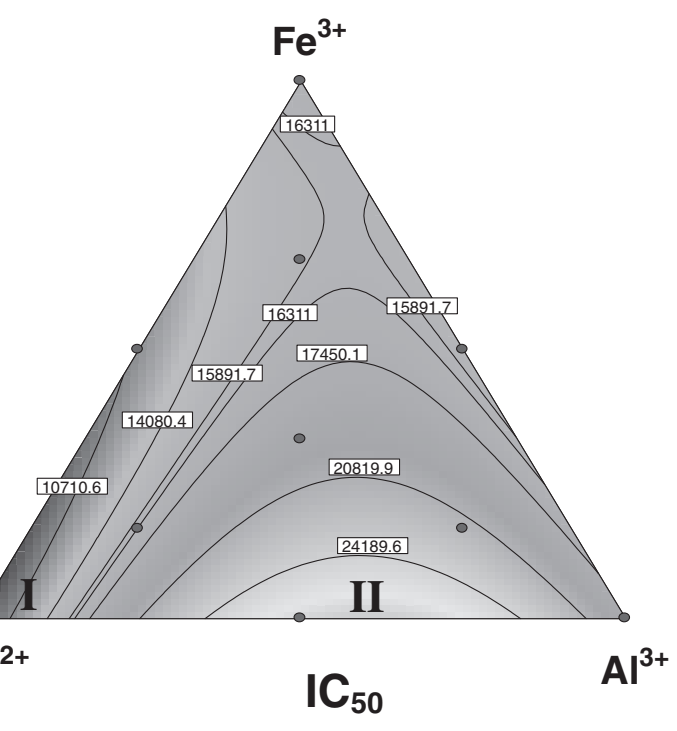

$\mathrm{Mn}^{2+}$

Fig. 7 (a) Three-dimensional and (b) two-dimensional contour plot of the $I C_{50}$ value for the mixture of $\mathrm{Fe}^{3+}, \mathrm{Mn}^{2+}$ and $\mathrm{Al}^{3+}$ ions.

when the ratio of released metal ions approaches region II. However, further dose-response experiments are still required to determine the toxicity of metal ions released from implant materials into surrounding tissues.

\section{Conclusions}

The toxicity of $\mathrm{Fe}^{3+}, \mathrm{Mn}^{2+}$, and $\mathrm{Al}^{3+}$ metal ions with respect to Escherichia coli DH5 $\alpha$ is in an order of $\mathrm{Mn}^{2+}>\mathrm{Fe}^{3+}>\mathrm{Al}^{3+}$. The $I C_{50}$ values for solutions containing two or three kinds of metal ions exhibit deviations from the expected additive toxicity because the interactions between the metal ions cause synergistic or antagonistic effects. The $I C_{50}$ values contour plot for the mixture of $\mathrm{Fe}^{3+}$, $\mathrm{Mn}^{2+}$, and $\mathrm{Al}^{3+}$ ions shows a saddle region close to $\mathrm{Mn}^{2+}$ and a hump region around $\mathrm{Mn}^{2+}: \mathrm{Al}^{3+}=1: 1$. Fe-Mn-Al ternary alloys may risk increased toxicity when the ratio of metal ions released from it in human tissue is close to the saddle region in the augmented simplex model contour plot. Fe-Mn-Al ternary alloys may risk a lower toxicity for prostheses applications when the ratio of released metal ions approaches the hump region in the contour plot. The toxicity tests using bacteria in this study can be useful and applicable to estimate the toxicity of metal ions in aqueous environment.

\section{Acknowledgements}

The authors gratefully acknowledge the financial support for this research provided by the National Science Council (NSC), Taiwan, Republic of China, under Grant No. NSC102-2221-E-197-006.

\section{REFERENCES}

1) M. Niinomi: Metall. Mater. Trans. A 33 (2002) 477-486.

2) M. Sumita, T. Hanawa and S. H. Teoh: Mater. Sci. Eng. C 24 (2004) 753-760.

3) J. Ballarre, I. Manjubala, W. H. Schreiner, J. C. Orellano, P. Fratzl and
S. Ceré: Acta Biomater. 6 (2010) 1601-1609.

4) V. N. Malheiro, R. L. Spear, R. A. Brooks and A. E. Markaki: Biomaterials 32 (2011) 6883-6892.

5) M. A. Costa and M. H. Fernandes: J. Mater. Sci. Mater. Med. 11 (2000) 141-153.

6) H. Takahashi, M. Kinbara, N. Sato, K. Sasaki, S. Sugawara and Y. Endo: Int. Immunopharmacol. 11 (2011) 1534-1540.

7) V. D'Antò, A. Eckhardt, K. A. Hiller, G. Spagnuolo, R. Valletta, L. Ambrosio, G. Schmalz and H. Schweikl: Biomaterials 30 (2009) 14921501 .

8) K. Otsuka and X. Ren: Prog. Mater. Sci. 50 (2005) 511-678.

9) P. Filip, J. Lausmaa, J. Musialek and K. Mazanec: Biomaterials 22 (2001) 2131-2138

10) J. Y. Xiong, Y. C. Li, X. J. Wang, P. D. Hodgson and C. E. Wen: J. Mech. Behav. Biomed. Mater. 1 (2008) 269-273.

11) S. A. Shabalovskaya: Bio-Med. Mater. Eng. 6 (1996) 267-289.

12) K. Takamura, K. Hayashi, N. Ishinishi, T. Yamada and Y. Sugioka: J. Biomed. Mater. Res. 28 (1994) 583-589.

13) M. G. Shettlemore and K. J. Bundy: J. Biomed. Mater. Res. 45 (1999) $395-403$.

14) S. H. Chang, B. Y. Chen and Y. C. Lin: Mater. Sci. Eng. C 32 (2012) 1893-1896.

15) J. G. Duh and C. J. Wang: J. Mater. Sci. 25 (1990) 2063-2070.

16) T. S. Shun, C. M. Wan and J. G. Byrne: Scr. Metall. 25 (1991) 17691774.

17) K. H. Hwang, C. M. Wan and J. G. Byrne: Mater. Sci. Eng. A 132 (1991) 161-169.

18) W. C. Cheng, C. F. Liu and Y. F. Lai: Scr. Mater. 48 (2003) 295-300.

19) T. Omori, K. Ando, M. Okano, X. Xu, Y. Tanaka, I. Ohnuma, R. Kainuma and K. Ishida: Science 333 (2011) 68-71.

20) K. Ando, T. Omori, I. Ohnuma, R. Kainuma and K. Ishida: Appl. Phys. Lett. 95 (2009) 212504.

21) R. L. W. Messer and L. C. Lucas: Dent. Mater. 15 (1999) 1-6.

22) R. L. W. Messer, S. Bishop and L. C. Lucas: Biomaterials 20 (1999) 1647-1657.

23) Y. Okazaki and E. Gotoh: Mater. Sci. Eng. C 33 (2013) 1993-2001.

24) D. J. Finney: Probit Analysis, (Cambridge University Press, London, 1971).

25) B. Y. Chen, H. L. Liu, Y. W. Chen and Y. C. Chen: Process. Biochem. 39 (2004) 737-748.

26) B. Y. Chen and J. S. Chang: Biotechnol. Prog. 21 (2005) 1085-1092.

27) B. Y. Chen, C. H. Wu and J. S. Chang: Bioresour. Technol. 97 (2006) 1880-1886.

28) J. M. Gozálvez and J. C. García-Díaz: J. Chem. Educ. 83 (2006) 647650 . 